\title{
Mycobacterium caprae - the first case of the human infection in Poland
}

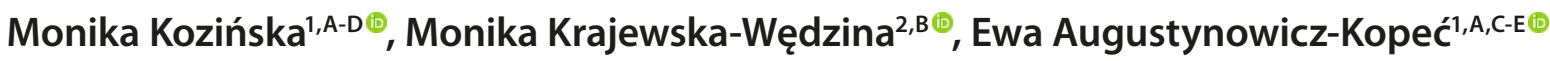 \\ ${ }^{1}$ Department of Microbiology, National Tuberculosis and Lung Diseases Research Institute (NTLD), Warsaw, Poland \\ 2 Department of Microbiology, National Veterinary Research Institute (NVRI), Puławy, Poland \\ $A$ - Research concept and design, B - Collection and/or assembly of data, C - Data analysis and interpretation, \\ $D$ - Writing the article, E - Critical revision of the article, F - Final approval of article
}

Kozińska M, Augustynowicz-Kopeć E, Krajewska-Wędzina M. Mycobacterium caprae - the first case of the human infection in Poland. Ann Agric Environ Med. 2020; 27(1): 151-153. doi: 10.26444/aaem/108442

\begin{abstract}
The strain of tuberculous mycobacteria called Mycobacterium caprae infects many wild and domestic animals; however, because of its zoonotic potential and possibility of transmission between animals and humans, it poses a serious threat to public health. Due to diagnostic limitations regarding identification of MTB strains available data regarding the incidence of $M$. caprae, human infection does not reflect the actual size of the problem. Despite the fact that the possible routes of tuberculosis transmission are known, the epidemiological map of this zoonosis remains underestimated. The progress in diagnostic techniques, application of advanced methods of mycobacterium genome differentiation and cooperation between scientists in the field of veterinary medicine and microbiology, have a profound meaning for understanding the phenomenon of bovine tuberculosis and its supervise its incidence. This is the first bacteriologically confirmed case of human infection of M. caprae in Poland.
\end{abstract}

- Key words

bovine tuberculosis, Mycobacterium bovis, Mycobacterium caprae, zoonosis

\section{INTRODUCTION}

Among the members of Mycobacterium tuberculosis complex (MTBC), tuberculosis (TB) in humans is mainly caused by $M$. tuberculosis, while bovine tuberculosis (bTB) results mostly from infection with $M$. bovis detected in wild and domestic mammals [1]. Since bovine mycobacteria causes clinical, radiological and pathological symptoms similar to $M$. tuberculosis, these strains can be distinguished only using special diagnostic techniques, such as culture, strain identification based on the biochemical and morphological features, and genotyping. Until recently, one of the criteria for differentiation of $M$. bovis was also resistance to pyrazinamide (PZA); however, PZA-susceptible strains of $M$. bovis have been described. As a consequence, $M$. bovis was split into two subspecies: $M$. bovis subsp. bovis, which showed resistance to PZA, and M. bovis subsp. caprae, which was sensitive to PZA. $M$. caprae has been identified in several European countries, including Spain, Austria, Italy, Croatia and Germany, and it is not solely restricted to the caprine host; $M$. caprae has been isolated from sheep, red deer, cattle, wild boar, from humans and captive animals, such as the Siberian tiger, camel and bison [2-11]. To-date, in Poland, M. caprae has been identified in cattle and wild animals, but until now no such case has been documented in humans [12]. As described, Polish strains classified as $M$. caprae and $M$. bovis have not acquired environmental resistance. $M$. caprae strains revealed sensitivity to all anti-mycobacterial drugs tested, and $M$. bovis isolates showed natural resistance only to PZA [13].

Address for correspondence: Monika Kozińska, Tuberculosis and Lung Diseases Research Institute, Poland

E-mail: m.kozinska@igichp.edu.pl

Received: 31.12.2018; accepted: 12.04.2019; first published: 20.05 .2019

\section{MATERIALS AND METHOD}

In November 2012, a 46-year-old male was admitted to the pulmonology department in one of the district hospitals in the Silesian Province of south-western Poland. The patient was cachectic, in a weak general condition, with dyspnea and dysarthria. In the last six months he had lost $12 \mathrm{~kg}$ of body weight and had a severe cough with haemoptysis. The patient was living alone, had been unemployed for 20 years, living on pension and had been a smoker for many years. Psychiatric consultation revealed organic disorders caused by chronic alcohol abuse. The man denied that he has had tuberculosis in the past or contacted a sick person with TB. Basic laboratory testing of blood and urine was performed, as well as chest X-ray and tuberculin test. Sputum was sampled for bacteriological testing. Identification of the grown strain was performed with molecular testing (GenoTypeMTBC, Hain Lifescience). Drug sensitivity was determined with the genetic method GenoTypeMTBplus/sl (HainLifescience) and on LJ medium, according to the methods used in all laboratories for mycobacterium in Poland. Genomic DNA was isolated using hexadecyltrimethylammonium bromide [14]. Genotyping of the strain was carried out according to the described methodology, using spoligotyping [15].

\section{RESULTS AND DISCUSSION}

In most developed countries, including Poland, after the introduction in the middle of the last century of means for controlling tuberculosis, the threat of bovine tuberculosis in human decreased significantly [1]. The simultaneous implementation of appropriate eradication and surveillance programmes has resulted in the fact that in 2009 Poland obtained the status of being free from this zoonotic disease. 
To-date in Poland, bovine mycobacteria have not been isolated in humans and the presented case is the first bacteriologically confirmed infection with $M$. caprae.

Chest X-Ray performed on admission revealed infiltration and necrosis in the superior field of the left lung and in the apex of the right lung, as well as disseminated mottling lesions in the medial fields, and less pronounced in the inferior fields of both lungs. The tuberculin test amounted to $18 \mathrm{~mm}$.

The direct sputum test for TB detected acid-fast mycobacteria and four weeks of incubation on Löwenstein-Jensen (LJ) medium resulted in the growth of Mycobacterium (Fig. 1). Initial identification in the hospital laboratory confirmed that the isolated strain belonged to the group of Mycobacterium tuberculosis. The drug resistance test performed with a standard method showed sensitivity to streptomycin (SM), isoniazid (INH), rifampicin (RMP), ethambutol (EMB) and pyrazinamide (PZA). Strain identification methods detected that the strain belonged to Mycobacterium caprae. During spoligotyping, the DNA pattern of the strain was obtained - a unique spoligotype 200003757377600 , not registered in international spoligotypes databases SpolDB4 and SITVIT WEB, but noted in the Mycobacterium bovis spoligotype database (Mbovis. org) as SB1690 - a Spanish isolate from 2009 (Tab. 1).

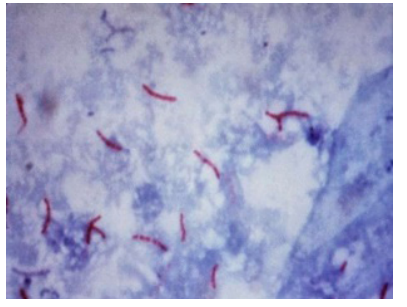

(A)

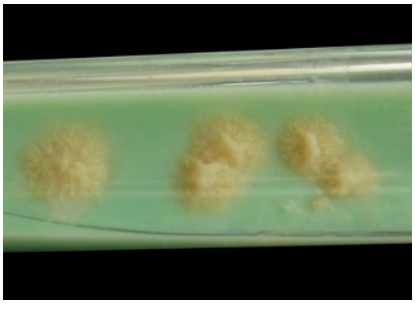

(B)
Figure 1. Sputum stained by the Ziehl-Neelsen method; $(A)$ with visible mycobacteria, (B) colonies of Mycobacterium grown after 4 weeks of incubation on LJ medium

Table 1. Characteristic of the grown strain

\begin{tabular}{|c|c|}
\hline \multicolumn{2}{|r|}{ Results of microbiological and molecular testing } \\
\hline Clinical material & Sputum \\
\hline Bacterioscopy & ++ \\
\hline Culture & Growth after 4 weeks on LJ medium \\
\hline $\begin{array}{l}\text { Phenotype of } \\
\text { drug resistance }\end{array}$ & Sensitive to SM, INH, RMP, EMB, PZA \\
\hline $\begin{array}{l}\text { Strain } \\
\text { identification }\end{array}$ & Mycobacterium caprae \\
\hline Spoligotyping & $\begin{array}{l}\text { Hybridization pattern } \\
\text { Octagonal pattern } 200003757377600 \\
\text { Not registered in SpolDB4 and SITVIT WEB, but registered in } \\
\text { Mbovis. Org. as SB1690 - Spanish isolate from } 2009\end{array}$ \\
\hline
\end{tabular}

After administration of rifampicin, streptomycin and pyrazinamide, the patient's somatic and clinical condition improved. After 127 days of hospitalization, an early eradication was achieved. The patient was discharged and remained under supervision of the pulmonology out-patient clinic.

It was demonstrated that the transmission of bTB to humans most often occurs through inhalation, during direct contact of the human withan infected animal, or with food as a result of consumption of unpasteurized cow/s milk contaminated with mycobacteria. Indirect exposure mainly concerns people exposed to the source of infection at work (farmers, veterinarians, people working with meat and workers in slaughterhouses), as well as during recreational activities (hunters in contact with contaminated animals) [16].

In the presented case, however, the source of infection remained unknown, and based on the patient's history, he did not have contact with a person with tuberculosis and for a longer time had not been close to the farm animals, which were not tested for tuberculosis. In addition, a comparative analysis of a spoligotype of isolated strain (200003757377600) and spoligotypes of $M$. caprae strains isolated from 52 Polish cattle and wild animals, previously described by KrajewskaWędzina M., excluded the genetic relatedness and possible epidemiological link between isolates.

Data on bovine tuberculosis caused by $M$. caprae in humans are limited, registers are not precise and detailed diagnostics are complex and expensive. First of all, clinical differentiation between tuberculosis induced by $M$. caprae and and $M$. tuberculosis is practically impossible [17]. Secondlyn tuberculosis caused by $M$. caprae more often presents with extrapulmonary manifestation, which makes the microbiological confirmation of the infection even more difficult [18]. In addition, not all diagnostic laboratories have appropriate equipment to perform specialist testing based on the analysis of the mycobacterial genome. The precise identification of the strain isolated in humans is necessary from both the therapeutic and epidemiological point of view. In case of infection of $M$. bovis, which is resistant to PZA, it is necessary is excluded this medicine from therapy. On the other hand, infection with M. caprae can be successfully treated with pyrazinamide. In the presented case, the identified strain was sensitive to all drugs administered, including PZA. In addition, the radiological and clinical presentation suggested standard tuberculosis caused by M. tuberculosis. Only the usage of molecular methods for identification of the strain enabled the correct diagnosis to be made.

In Europe, bTB is most frequently caused by $M$. bovis and less frequently by $M$. caprae [19]. Therefore, a case of bovine tuberculosis in humans is believed to be equivalent to infection with M. bovis. However, cases of tuberculosis caused by $M$. caprae are not identified due to diagnostic difficulties. To improve the registration of bovine tuberculosis in Poland it is necessary to increase the supervision of people who are in direct contact with affected animals.

\section{Conflicts of interest}

The authors do not report any conflict of interest.

\section{Acknowledgments}

The study was undertaken as part of the fin project sponsored by the Jakub Hr. Potocki Foundation, and as a part of the statutory activity of the Institute of Tuberculosis and Lung Diseases (Research Task No. 1.27). The research was financed from the statutory funds of the National Veterinary Research Institute in Pulawy, Task No. S/340. 


\section{REFERENCES}

1. O'Reilly LM, Daborn CJ. The epidemiology of Mycobacterium bovis infections in animals and man: a review. Tuber Lung Dis. 1995; 76: 1-46.

2. Chiari M,Zanoni M, Alborali LG, Zanardi G, Avisani D, Tagliabue S, et al. Isolation of Mycobacterium caprae (Lechtal genotype) from red deer (Cervus elaphus) in Italy. J Wildl Dis. 2014; 50(2): 330-333. doi: 10.7589/2013-06-135.

3. Cvetnic Z, Katalinic-Jankovic V, Sostaric B, Spicic S, Obrovac M, Marjanovic $S$, et al. Mycobacterium caprae in cattle and humans in Croatia. Int J Tuberc Lung Dis. 2007; 11(6): 652-658.

4. Fink M, Schleicher C, Gonano M, Prodinger WM, Pacciarini M, Glawischnig W, et al. Red deer as maintenance host for bovine tuberculosis, Alpine region. Emerg Infect Dis. 2015; 21(3): 464-467. doi: 10.3201/eid2103.141119.

5. Hansen N, Seiler C, Rumpf J, Kraft P, Dlaske H, Abele-Horn M, et al. Human Tuberculous Meningitis Caused by Mycobacterium caprae. Case Rep Neurol. 2012; 4(1): 54-60. doi: 10.1159/000337299.

6. Kubica T, Rüsch-Gerdes S, Niemann S. Mycobacterium bovis subsp. caprae caused one-third of human M. bovis-associated tuberculosis cases reported in Germany between 1999 and 2001. J Clin Microbiol. 2003; 41(7): 3070-3077.

7. Lantos A, Niemann S, Mezõsi L, Sós E, Erdélyi K, Dávid S, et al. Pulmonary tuberculosis due to Mycobacterium bovis subsp. caprae in captive Siberian tiger. Emerg Infect Dis. 2003; 9(11): 1462-1464.

8. Muñoz Mendoza M, Juan Ld, Menéndez S, Ocampo A, Mourelo J, Sáez JL, et al. Tuberculosis due to Mycobacterium bovis and Mycobacterium caprae in sheep. Vet J. 2012; 191(2): 267-269. doi: 10.1016/j.tvjl.2011.05.006

9. Parra A, Fernández-Llario P, Tato A, Larrasa J, García A, Alonso JM, et al. Epidemiology of Mycobacterium bovis infections of pigs and wild boars using a molecular approach. Vet Microbiol. 2003; 97(1-2): 123-133.

10. Prodinger WM, Eigentler A, Allerberger F, Schonbauer M, Glawischnig W. Infection of red deer, cattle, and humans with Mycobacterium bovis subsp. caprae in western Austria. J Clin Microbiol. 2002; 40: 2270-2272.
11. Rodríguez E, Sánchez LP, Pérez S, Herrera L, Jiménez MS, Samper S, et al. Human tuberculosis due to Mycobacterium bovis and M. caprae in Spain, 2004-2007. Int J Tuberc Lung Dis. 2009; 13(12): 1536-1541.

12. Krajewska-Wędzina M, Kozińska M, Orłowska B, Weiner M, Szulowski K, Augustynowicz-Kopeć E, et al. Molecular characterisation of Mycobacterium caprae strains isolated in Poland. Vet Rec. 2018; 182: 292.

13. Krajewska-Wędzina M, Zabost A, Augustynowicz-Kopeć E, Weiner M, Szulowski K. Evaluation of susceptibility to antimycobacterial drugs in Mycobacterium Tuberculosis complex strains isolated from cattle in Poland. J Vet Res. 2017; 61(1): 23-26. doi: 10.1515/jvetres-2017-0003.

14. van Embden JD, Cave MD, Crawford JT, Dale JW, Eisenach KD, Gicquel B, et al. Strain identifcation of Mycobacterium tuberculosis by DNA fngerprinting: recommendations for a standardized methodology. J Clin Microbiol. 1993; 31: 406-409.

15. Kamerbeek J, Schouls L, Kolk A, van Agterveld M, van Soolingen D, Kuijper S, et al. Simultaneous detection and strain differentiation of Mycobacterium tuberculosis for diagnosis and epidemiology. J Clin Microbiol. 1997; 135: 907-914.

16. Langer AJ, Lo Bue PA. Public health significance of zoonotic tuberculosis caused by the Mycobacterium tuberculosis complex. In: Thoen CO, Steele JH, Kannene JB, editors. Zoonotic Tuberculosis: Mycobacterium bovis and Other Pathogenic Mycobacteria. 3rd ed. 2014. p. 21-33.

17. Niemann S, Richter E, Rusch-Gerdes S. Differentiation among members of the Mycobacterium tuberculosis complex by molecular and biochemical features: evidence for two pyrazinamide-susceptible subtypes of M. bovis. J Clin Microbiol. 2000; 38: 152-157.

18. de la Rua-Domenech R. Human Mycobacterium bovis infection in the United Kingdom: Incidence, risks, control measures and review of the zoonotic aspects of bovine tuberculosis. Tuberculosis. 2006; 86: 77-109.

19. Schiller I, Waters WR, Vordermeier HM, Jemmi T, Welsh M, Keck N, et al. Bovine tuberculosis in Europe from the perspective of an officially tuberculosis free country: trade, surveillance and diagnostics. Vet Microbiol. 2011; 151(1-2): 153-159. doi: 10.1016/j.vetmic.2011.02.039.

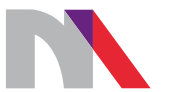

Ministry of Science and Higher Education

Republic of Poland

Generation of the DOI (Digital Object Identifier) - task financed under the agreement No. 618/P-DUN/2019 by the Minister of Science and Higher Education 